\title{
Readability Formulas and Cohesive Markers in Reading Comprehension
}

\author{
Abbas Ali Rezaee \\ Faculty of Foreign Languages and Literatures, University of Tehran, Iran \\ Email: aarezaee@ut.ac.ir \\ Mohammad Hussein Norouzi \\ Faculty of Foreign Languages and Literatures, University of Tehran, Iran \\ Email: norouzi1221@yahoo.com
}

\begin{abstract}
Matching reading materials to learners with the appropriate level of proficiency has been the focus of attention for many scholars. To this end, readability formulas have been developed. Despite being efficient and user friendly, the formulas have not been able to stand to the test of research, thus undergoing some criticism on the grounds that they are not sensitive to the modification in the factors they are based on. Furthermore, they fail to consider other factors which play roles in the comprehension of written materials. Some scholars, based on such criticisms, have noticed the absence of some factors in readability formulas. Some of these factors are cultural origin, structure of theme and core/non-core words, and conjunctions. The present study constitutes an attempt to investigate the relationship between readability of written materials and the learners' performance at two proficiency levels of intermediate and advanced, the relationship between cohesion markers (grammatical markers, conjunctions and lexical markers) and the readability of written materials, and also the relationship between these cohesion markers and the performance of learners of English as a foreign language at the two aforementioned proficiency levels. To calculate the readability of the material, two prominent readability formulas, Flesch and Fog Index, were employed. The results indicated a significant correlation between the readability of passages and the learners' performance at both levels. Only grammatical cohesion markers were shown to be significantly correlated with the readability of the written materials. The learners' performance correlated significantly with grammatical cohesion markers at intermediate level and with lexical cohesion markers at advanced level.
\end{abstract}

Index Terms - cohesion markers, performance, proficiency, readability formulas, reading comprehension, reading materials

\section{INTRODUCTION}

One of the most important issues in the realm of ESL/EFL research has been the match between the materials and the proficiency level of those who receive or use them. This plays a crucial role in material sequencing and gradation. Some methods have been developed to create a match between learners' proficiency and the difficulty level of written materials. This issue acquires even greater momentum with regard to the fact that, in many cases, written material comprises the main source for most language learners, most prominently in academic and higher educational fields. Subjective methods such as teacher or reader judgments have been inadequate due to their very nature. In order to overcome the subjectivity of these methods and its consequences, objective ways have been designed to measure the difficulty level of written materials for the purpose of matching them to suitable level of the readers' proficiency. The dependability of these objective methods has in turn been rightly subject to criticism and research both theoretically and empirically. The present study attempts to investigate whether readers' comprehension is correlated with the difficulty of texts determined by readability formulas. Moreover, it tends to study the relationship between the existence of cohesive markers in texts and students' comprehension of them. This study is of prime importance because readability formulas have received many theoretical and empirical criticisms.

\section{LITERATURE REVIEW}

\section{A. Readability Formulas}

Readability formulas used for measuring the readability level, "comprehensibility of written text" Homan, Hewitt \& Linder (2005), vary in definition. Bruce and Robin (1988) argue that readability formulas are procedures for assigning to a text a numerical estimate of 'readability' which is previously defined by scholars as "ease of reading", "interest", or "ease of understanding" (P.5). A formula is, in fact, a regression equation used to predict comprehension. To obtain a comprehension measure, the variables, namely word and sentence length, should be measured and then fed into the calculation (Baker, Atwood \& Duffy 1988). Redish (as cited in Allen, 1985, P. 215) defines the formulas as "mathematical equations for predicting the level of reading ability needed to understand a particular piece of prose". 
According to Klare (1963), there have been over 100 readability formulas developed, all based on the same underlying model of reading process, and due to the ease of application, some of them have acquired popular use. Most readability formulas have made use of linguistic elements to calculate readability. These elements include semantic and syntactic complexity. Semantic complexity is measured by the length of words in terms of the number of letters or syllables present or the words' absence or presence in specific word lists. Syntactic complexity is analyzed at the sentence level and its most common measure is the number of words per sentence.

Due to the large number of formulas and the disagreement on their scales, Powers, Summer and Kearl (1958) reexamined four major formulas, namely, Flesch, Dale-Chall, Fog Index and Farr-Jenkins-Paterson, in order to develop consistency among the grades they yielded. Flesch formula, one of the most popular readability formulas in use, uses sentence length in terms of words and the number of syllables per 100 words. Dale-Chall is another formula which considers sentence length and the number of words outside Dale list of 3000 familiar words. Fog Index, another widely used formula, relies on sentence length and the number of polysyllabic words, i.e. words with three or more syllables. Farr-Jenkins-Paterson is yet another readability formula which relies on sentence length and the number of monosyllables for its calculation.

These formulas have been used with some success, but they have also been criticized by some scholars. The criticism on the formulas constitutes two main areas; these areas correspond to the two basic factors that most readability formulas use, that is, word difficulty and sentence length. Urqhart (1985) as well as Anderson and Davison (1988) found that simplifying the text through using simpler words does not result in a better comprehension of the text. Blau's (1982), Anderson and Davison (1988), Baker et al (1988), Davison and Green (1988), and Rezaei (2000) argued that splitting up the complex sentences into simple sentences and thus reducing syntactic complexity does not affect the comprehension of readers.

Such criticisms, which are based on experiments mentioned above, along with the theoretical criticism on the formulas' failure to consider other elements that play a role in comprehension, such as 'discourse cohesion characteristics', 'the number of inferences required', 'the complexity of ideas', 'rhetorical structure' and 'dialect', and also reader-based factors such as background and motivation (Bruce \& Robin, 1988), inspired the consideration of the effect of other elements on reading comprehension. Metaphoric language use, in turn, would affect the learners' performance on reading comprehension tasks. Idioms, as a main area of metaphoric language use, constitute a considerable part of any language. The use of lexical items for different concepts hinges on metaphoricity of language and is based on the similarity of objects and concepts.

Jonson (as cited in Carrel, 1987) found that cultural origin was an effective factor in the comprehension of prose by readers. Akbari, Atae and Marefat (1999) considered different kinds of themes and core/non-core words as the possible predictors of comprehension and concluded that clauses as themes are better predictors for advanced learners' comprehension, while non-core words seem to be more suitable for intermediate level learners' comprehension. Geva (1992) carried out a study, investigating the relationship between conjunctions in a text and advanced college students' ability to comprehend the text. He found a high correlation between the conjunctions in a text and the readers' comprehension of it and suggested conjunctions as a predictor of the comprehension of authentic academic materials. His findings inspired the question of whether other cohesion markers, of which conjunctions constitute one type, can also be predictors of comprehension or not.

\section{B. Cohesion Markers}

Cohesion, a semantic concept, as Halliday and Hasan (1984) puts it, is the relations of meaning within a text that confers on a stretch of language what make it a text. Cohesion relies on presupposition and occurs when the interpretation of one element is dependent on that of another. When such a relation, a tie, occurs between the presupposing and the presupposed elements, cohesion is created. Cohesion is accommodated in linguistic form in the realm of language. Since sentences, as structures, are inherently cohesive, the concept of cohesion is used to denote the cross-sentential tie and relies on grammatical or lexical means for its existence.

Cohesion encompasses four general categories. Two categories are grammatical, one is lexical, and the last one on the border between grammatical and lexical. Reference along with substitution and ellipsis are grammatical, substitution and ellipsis being one category, for ellipsis is considered as substitution by nothing. Conjunctions are on the border as benchmarks hinting at cross-sentential meaning relations while they impose some grammatical structures. The last kind is lexical and covers the concepts of reiteration and synonymy, the repetition of identical or very similar concepts throughout the text. The repeated or related concepts are amenable to various grammatical forms.

\section{THE PRESENT STUDY}

The present study aims to investigate whether there is any relationship between readability of texts and students' comprehension of them. Moreover, the existence of any relationship between the number of cohesive markers existing in a texts and the students' comprehension of them is to be investigated. As readability formulas as measures of getting information about difficulty level of texts has been criticized be various experts, investigating their impact on students' reading comprehension is of paramount importance. On the other hand, cohesive markers, signals for creating more coherent texts, can be a serious concern in the process of reading comprehension. 
The present study addresses the following research questions.

1. Does difficulty level of texts (determined by readability formulas) significantly correlate with students' reading comprehension?

2. Is there any relationship between ease/difficulty of texts and the cohesive markers in them?

3. Is there any relationship between difficulty level of texts (determined by cohesive markers existing in them) and students' reading comprehension?

\section{A. Participants}

The data based on which the analyses in the present study have been done are collected from the total number of 124 participants. These participants included 50 English language learners at Open Center for Art and Cultural Education, an affiliate of Tehran University, $74 \mathrm{MA}, \mathrm{MSc}$ and $\mathrm{PhD}$ candidates from the University of Tehran, Iran University of Science and Technology and Shahid Beheshti University in the fields of science and humanities. The participants were both male and female students. However, gender factor was not taken into account in this study. It is worth mentioning that both male and female students had taken part in the entrance examination and had equal chance of getting admitted. Moreover, care was taken not to include gender-biased texts for collecting the necessary data. The participants were divided into two groups of intermediate and advanced based on their performance on Nelson Quick Check test.

\section{B. Grouping}

Out of these 124 participants, 28 participants were excluded due to their failure to answer all of the questions, 1 for falling below 50 and 2 for falling above 80 on Nelson Quick Check test; these scores were considered outliers, very high or very low compared with other scores and with a rare frequency. Then the remaining 93 scores underwent descriptive statistics and the scores half a standard deviation below and half a standard deviation above the mean were excluded to ensure a considerable difference between the two groups of participants. The number of the participants thus excluded was 31. The number of scores half a standard deviation below the mean was 36 and that of the score half a standard deviation above the mean was 31 . The former group was considered the intermediate and the latter advanced. As such, the total number of the scores that entered into the final data analysis was $67 ; 36$ for intermediate level and 31 for the advanced level. The descriptive statistics for the placement of participants are shown in Table 1.

TABLE 1

DESCRIPTIVE STATISTICS FOR NELSON SCORE OF PARTICIPANTS

\begin{tabular}{|l|l|l|l|l|l|}
\hline & $\mathrm{N}$ & Minimum & Maximum & Mean & Std. Deviation \\
\hline Nelson Score & 93 & 50.00 & 80.00 & 65.9462 & 8.82482 \\
Valid N (listwise) & 93 & & & & \\
\hline
\end{tabular}

In order to make sure of the significance of the difference between the two groups, an independent-samples t-test was run. Since the t-critical for $65 \mathrm{df}$ is 2.000 and the t-value from the t-test is 23.178 , much greater than 2.000 , the significance of their difference was strongly established. Moreover, the significance value was found to be 0.000 , far less than the significance level of 0.05 . The results are shown in Table 2.

TABLE 2

INDEPENDENT SAMPLES TEST FOR NELSON QUICK CHECK TEST SCORES OF THE TwO LEVELS

\begin{tabular}{|c|c|c|c|c|c|c|c|c|}
\hline & & \multicolumn{2}{|c|}{$\begin{array}{l}\text { Levene's Test for } \\
\text { Equality of Variances }\end{array}$} & \multicolumn{5}{|c|}{ t-test for Equality of Means } \\
\hline & & $\mathrm{F}$ & Sig. & $\mathrm{t}$ & df & $\begin{array}{l}\text { Sig. (2- } \\
\text { tailed) }\end{array}$ & $\begin{array}{l}\text { Mean } \\
\text { Difference }\end{array}$ & $\begin{array}{l}\text { Std. Error } \\
\text { Difference }\end{array}$ \\
\hline \multirow[t]{2}{*}{$\begin{array}{l}\text { Nelson } \\
\text { Score }\end{array}$} & $\begin{array}{l}\text { Equal variances } \\
\text { assumed }\end{array}$ & 2.451 & .122 & 23.545 & 65 & .000 & 19.31900 & .82053 \\
\hline & $\begin{array}{l}\text { Equal variances } \\
\text { not assumed }\end{array}$ & & & 23.178 & 57.707 & .000 & 19.31900 & .83351 \\
\hline
\end{tabular}

\section{Material}

Ten reading passages were chosen out of five practice tests from Phillips's Longman Preparation for the TOEFL Test, (1996). The reading passages were chosen so as to yield as wide a range of readability levels as possible. The criterion for their choice was their mean of Flesch and Fog Index of Readability indices. The passages were ordered from the lowest to the highest in terms of their readability index. Each of these reading passages included ten questions, mounting to 100 questions for the whole test.

Three types of cohesive markers, i.e., conjunctions, grammatical and lexical, were taken into account. There markers were counted in all the ten reading passages. Table 4 presents the relevant the readability indices of the ten passages determined by Flesch and Fog Index of readability. It also shows the number of the above-mentioned cohesive markers in the passages. 
TABLE 3

THE READABILITY INDICES AND THE FREQUENCY OF COHESIVE MARKERS IN ALL TEN PASSAGES

\begin{tabular}{|c|c|c|c|c|c|c|}
\hline Texts $\quad$ Variables & Flesch & Fog Index & $\begin{array}{l}\text { Readability } \\
\text { mean }\end{array}$ & Conjunctions & Grammatical & Lexical \\
\hline 1 & 5.3 & 5.3 & 5.30 & 2 & 44 & 33 \\
\hline 2 & 5.4 & 5.5 & 5.45 & 3 & 33 & 48 \\
\hline 3 & 5.6 & 6.0 & 5.80 & 4 & 24 & 34 \\
\hline 4 & 5.8 & 6.2 & 6.00 & 6 & 45 & 21 \\
\hline 5 & 6.8 & 6.6 & 6.70 & 5 & 29 & 24 \\
\hline 6 & 6.6 & 7.0 & 6.80 & 6 & 27 & 30 \\
\hline 7 & 7.0 & 6.9 & 6.95 & 2 & 23 & 19 \\
\hline 8 & 7.3 & 7.1 & 7.20 & 5 & 28 & 20 \\
\hline 9 & 7.8 & 7.5 & 7.65 & 4 & 24 & 26 \\
\hline 10 & 8.0 & 7.8 & 7.90 & 8 & 20 & 23 \\
\hline
\end{tabular}

\section{Data Collection}

The participants were asked to read the ten passages and answer the reading comprehension questions. The incompletely answered tests were excluded and the remaining participants were divided into two groups, intermediate and advanced, based on their performance on Nelson Quick Check test. Next, the average score for each reading passage was calculated for each group. In this way, two sets of average scores were obtained, one based on the performances of the intermediate and the advanced groups respectively These average scores subsequently underwent the final data analysis, The scores are presented in Table 4.

TABLE 4

THE MEAN SCORES FOR THE TEXTS AT TWO PROFICIENCY LEVELS

\begin{tabular}{|l|l|l|l|l|}
\hline \multirow{2}{*}{ Texts } & Level & \multicolumn{1}{l|}{ Intermediate Level } & Advanced Level \\
\cline { 2 - 5 } & M & SD & M & SD \\
\hline 1 & 8.2 & 1.11 & 8.5 & 1.32 \\
\hline 2 & 7.0 & 0.89 & 9.4 & 1.07 \\
\hline 3 & 7.7 & 1.77 & 8.9 & 1.54 \\
\hline 4 & 7.9 & 1.49 & 8.2 & 1.38 \\
\hline 5 & 8.1 & 0.75 & 8.4 & 1.38 \\
\hline 6 & 8.0 & 1.71 & 9.1 & 0.97 \\
\hline 7 & 6.0 & 1.15 & 7.6 & 1.58 \\
\hline 8 & 5.4 & 1.78 & 7.8 & 1.62 \\
\hline 9 & 4.4 & 0.81 & 6.3 & 1.08 \\
\hline 10 & 4.7 & 2.60 & 5.7 & 1.87 \\
\hline
\end{tabular}

\section{RESULTS}

In order to check the consistency of the readability indices with the performance of the participants, they were analyzed for correlation. The results showed significantly high correlations at 0.05 and 0.01 for the intermediate and advanced levels respectively. Table 5 presents the correlation between readability grades and the participants' performance at each level.

TABLE 5

THE CORRELATION BETWEEN READABILITY GRADES WITH EACH LEVEL

\begin{tabular}{|l|l|l|l|l|}
\hline \multicolumn{2}{|l|}{} & Intermediate Level & Advanced Level \\
\hline Spearman's rho & Readability & $\begin{array}{l}\text { Correlation } \\
\text { Coefficient }\end{array}$ & $-.758^{*}$ & $-.806^{* *}$ \\
\hline & & Sig. (2-tailed) & .011 & .005 \\
\hline & & $\mathrm{N}$ & 10 & 10 \\
\hline
\end{tabular}

* Correlation is significant at the 0.05 level (2-tailed)

** Correlation is significant at the 0.01 level (2-tailed).

Then, these indices were compared with the frequency of cohesion markers to detect possible relations.

TABLE 6

THE CORRELATION BETWEEN READABILITY GRADES AND COHESION MARKERS

\begin{tabular}{|c|c|c|c|c|c|}
\hline & & & Conjunctions & Grammatical & Lexical \\
\hline \multirow[t]{3}{*}{ Spearman's rho } & \multirow[t]{3}{*}{ Readability } & Correlation Coefficient & .479 & $-.711 *$ & -.624 \\
\hline & & Sig. (2-tailed) & .162 & .021 & .054 \\
\hline & & $\mathrm{N}$ & 10 & 10 & 10 \\
\hline
\end{tabular}


As shown in the table above, only grammatical cohesive markers show a significant correlation with readability indices.

To find whether cohesion markers can be used as reliable predictors of reading comprehension, their correlations with the participants' performance were calculated. . The results are shown in Table 7.

TABLE 7

THE RESULTS OF SPEARMAN’S RHO CONDUCTED TO SEE THE RELATIONSHIP BETWEEN LEVEL OF PROFICIENCY AND THE NUMBER OF COHESIVE MARKERS IN TEXTS

\begin{tabular}{|c|c|c|c|c|}
\hline & & Conjunctions & Grammatical & Lexical \\
\hline \multirow[t]{2}{*}{ Intermediate Level } & $\begin{array}{l}\text { Correlation } \\
\text { Coefficient }\end{array}$ & -.117 & $.644(*)$ & .333 \\
\hline & Sig. (2-tailed) & .748 & .044 & .347 \\
\hline \multirow[t]{2}{*}{ Advanced Level } & $\begin{array}{l}\text { Correlation } \\
\text { Coefficient }\end{array}$ & -.227 & .529 & $.733(*)$ \\
\hline & Sig. (2-tailed) & .528 & .116 & .016 \\
\hline
\end{tabular}

The results show that there are significant correlations between grammatical cohesion markers and the intermediate level participants' performance, and between lexical cohesion markers and the advanced level participants' performance. This can mean that at a lower level of proficiency, grammatical cohesion markers could be reliable predictors of comprehension, whereas at higher levels, lexical cohesion markers could be possible indices for predicting reading comprehension.

\section{CONCLUSION AND DISCUSSION}

Many Scholars have criticized readability formulas as these formulas are considered insensitive towards the change in the factors included, word/sentence length and presence in a vocabulary list (Anderson \& Davison, 1988; Pearson, cited in Carrel, 1987; Urqhart, 1985; Anderson \& Davison, 1988; Rezaei, 2000). The findings of this study, however, confirm the agreement between readability indices and the performance of readers in the passages, and provide probable grounds for the use of readability formulas as a valid basis for ranking the written materials. The noteworthy point is that there is a basic difference between the studies in the literature and the present one. Almost unanimously, the studies criticizing the formulas manipulate and modify the factors used in the formulas to change readability index of the texts and study the consequences in the readers' comprehension, and in so doing, they violate the naturalness of these passages in many cases. The basic semantic foundation of the text does not undergo any or at least considerable modification while the means originally intended for its conveyance does. The overall discoursal impact and function of the passage would change, in some instances, dramatically. The modification or change of the means a writer is intent upon to convey a specific concept would affect the defection of the intended purpose. No recent studies have been reported on the factors per se in their intact state (Anderson \& Davison, 1988).

The suggestion made by Akbari et al. (1999) concerning the inclusion of more factors in readability measures proves worthwhile through the establishment of the relation between lexical and grammatical cohesive markers, factors absent from readability formulas, but considered in the present study. This study also provides justification for the claim that the more comprehensive the readability measures in terms of the factors included, the more reliable the measures would be. Such a claim would, of course, make readability formulas cumbersome in a way they would not be of much practicality. What would logically follow is the informed choice of the most determinant in comprehensibility and economical to be included in readability grade research and practice.

The possible existence of any meaningful relationship between the frequency of conjunctions in a passage and its comprehensibility was not exhibited in the present study. In the literature, on the contrary, however, Geva (1992) indicated the relationship between conjunctions and comprehension of authentic academic materials and justified the use of conjunctions as reliable predictors of comprehension. Findings of the present study, nonetheless, manifested no such relation. The low frequency of this type of discourse markers could be possible culprit; it varied between two and eight, a frequency much lower than that of other types of discourse markers considered here. Statistically, this rather short range decreases the variance, and a lower variance stands a lesser chance of comparing well. Further studies can illuminate the role of conjunctions in comprehensibility.

Cohesive markers and readability indices are, by their very nature, not necessarily expected to display any significant correlation. In the present study, however, a significant correlation between the readability indies and the set of grammatical cohesive markers is displayed. The practical validity and the nature of such a correlation should be further researched before being employed as a basis for readability judgment. Nevertheless, the different nature of readability indies and cohesive markers, by no means, obviate the inherent correlation each group is expected to have with the subjects' performance on reading comprehension tasks. The relationship between cohesive markers and comprehensibility at the two levels establishes the role of these factors in reading comprehension and verifies them as neglected factors that should be included in readability measures. 
The relationship between the subjects' performance and different subsets of cohesive markers at the two levels can provide us with clues as to the nature of reading comprehension and, with due caution and consideration, to its developmental process. The significant correlation between the intermediate participants' performance and the grammatical cohesive markers would be indicative of connectedness of reading performance with, or its partial dependence on the grammatical indices knitting the passage together as a link running through different parts of the passage. The significant correlation of the advanced level's performance with lexical cohesive markers hints at a strong engagement of the advanced level readers with the meaning aspect of a passage, which is regulated and systematized through the lexical cohesion markers.

With the very nature of these two types of cohesive markers in view, valuable insights would be drawn from the present findings, as to the developmental process of language, or to be precise, interlanguage. On these findings, one can claim that language learners resort to grammatical indices to get at the decoding of the whole passage at earlier stages, but as they proceed, their main point of reliance for comprehension is, at least partially, shifted towards lexical indices.

\section{REFERENCES}

[1] Akbari, R., Atae, M. R., \& Marefat, H. (1999), The Role of Discourse Elements in Determining the Readability of Texts. TESOL Quarterly, 31(1), 16-27.

[2] Allen, J. (1985). A readability review: Important trends since 1979. Teaching English in the two year college, 12(3), 214220 .

[3] Anderson, R. C., \& Davison, A. (1988). Conceptual and empirical bases of readability formulas. In A. Davison \& G. M. Green (Eds), Linguistic complexity and text comprehension: Readability issue reconsidered (PP. 23-54). Hillsdale, N J: Erlbaum.

[4] Baker, E. L., Atwood , N. K., \& Duffy, T. M. (1988). Cognitive approaches to assessing the readability of text. In A. Davison and G.M. Green (Eds), Linguistic complexity and text comprehension: Readability issue reconsidered (PP. 55-83). Hillsdale, N J: Erlbaum.

[5] Blau, E.K. (1982). The effect of syntax on readability for ESL students in Puerto Rico. TESOL Quarterly, 4, 517-527.

[6] Bruce, B., \& Robin, A. (1988). Readability formulas: Matching tools and task. In A. Davison, \& G. M. Green (Eds.), Linguistic complexity and text comprehension: Readability issue reconsidered (PP 5-22) Hillsdale, N J: Erlbaum.

[7] Carrell, P.L. (1987). Readability in ESL. Reading in a Foreign Language, 4, 21-40.

[8] Davison, A., \& Green, G. (1988). Introduction: In A. Davison \& G. M. Green (Eds), Linguistic complexity and text comprehension: Readability issue reconsidered, (PP. 1-4). Hillsdale NJ; Erlbaum.

[9] Geva, E. (1992). The Role of Conjunctions in L2 Text Comprehension. TESOL Quarterly, 26(4), 731-748.

[10] Halliday, M.A.K. and Hasan, R. (1984). Cohesion in English U.S.A: Longman.

[11] Homan, S., Hewitt, M., Linder, S. (2005). The development and validation of a formula for measuring single-sentence test item readability. DOI: 10.1111/j.1745-3984.1994.tb00452.x

[12] Klare, G. (1963). The measurement of readability. Ames Iowa: Iowa State University Press.

[13] Phillips, D. (1996). Longman Preparation for the TOEFL Test. Pearson Education: New York.

[14] Powers, R.D., Summer, W. A., and Kearl, B. E. (1958), A Recalculation of Four Adult Readability Formulas. Journal of Educational Psychology, 49 (2), 99-105.

[15] Rezaei, A. A. (2000). 'The Validity of the Fog-Index of Readability'. The Journal of Humanities of the Islamic Republic of Iran. 7(4).

[16] Urqhart, AH. (1985). The effect of rhetorical ordering on readability. In A. Anderson and A.H. Urqhart (Eds.), Reading in a foreign language. (PP. 161-180). Longman: London.

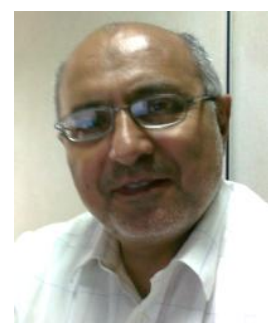

Abbas Ali Rezaee was born in Tehran, IR Iran, in 1956. He finished his MA in Teaching English as a Foreign Language (TEFL) in Tabiat Modarres University, Tehran, in 1989 and obtained his PhD in Applied Linguistics from the University of Exeter, England, in 2001.

He is currently a member of academic staff at the Department of English Language and Literature, Faculty of Foreign Languages and Literatures, University of Tehran. He has published many articles in national and international journals. He has taught specialized courses at BA, MA and PhD levels and has also supervised a large number of MA theses and $\mathrm{PhD}$ dissertation in language teaching and testing. His main research interests are Language Teaching, Language Testing, Discourse Analysis, ESP, and CALL.

Dr Rezaee is a member of the Teachers of English Language and Literature Society in Iran (TELLSI). He is the reviewer for a number of domestic and international journals.

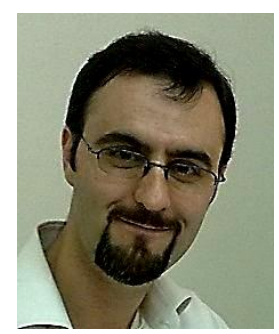

Mohammad Hussein Norouzi was born in Tabriz, Iran, in August 1979. He finished his BA in English language and literature at the University of Tabriz, Tabriz, Iran, in 2001. He did his MA at the University of Tehran (UT), Iran, in 2004, in the field of TEFL. At the moment, he is a PhD candidate at UT in TEFL.

He taught English Conversation in the 'Open Centre for Cultural Educations' from 2002 to 2005 and IELTS at 'Farhikhtegan-e Daneshgah' from 2005 to 2010, both of which are affiliates of the UT. Starting from 2006, he is currently a Lecturer at the UT. He has published an article entitled 'Self-Assessment' in ILI Language Teaching Journal, Volume 4, No. 1, (2008). His main research interest is 'Discourse Analysis' in Applied Linguistics. 